\title{
Effectiveness of Mobile Skill Teaching Software for Parents of Individuals with Intellectual Disability
}

\author{
Serkan Cankaya ${ }^{1} \&$ Abdullah Kuzu ${ }^{2}$ \\ ${ }^{1}$ Department of Computer Education and Instructional Technology, Necatibey Education Faculty, Balikesir \\ University, Balikesir, Turkey \\ ${ }^{2}$ Department of Computer Education and Instructional Technology, Education Faculty, Anadolu University, \\ Eskisehir, Turkey \\ Correspondence: Serkan Cankaya, Necatibey Education Faculty, Altieylul, Balikesir, Turkey. Tel: \\ 90-266-241-2762. E-mail: serkancankaya@balikesir.edu.tr
}

Received: August 25, 2017

Accepted: September 30, 2017

Online Published: February 25, 2018

doi:10.5539/ies.v11n3p1

URL: https://doi.org/10.5539/ies.v11n3p1

\begin{abstract}
Mobile skill teaching software has been developed for the parents of the children with intellectual disability to be used in teaching daily life skills. The purpose of this research is to investigate the effectiveness of the mobile skill teaching software developed for the use of the parents of the children with intellectual disability. In accordance, the effectiveness of the software has been tested using multiple probe design with probe conditions across subjects' research methodology which is one of the single subject research models. Four adults with intellectual disability and their parents participated in the study. The parents participating in the study taught their children with intellectual disability how to cook cheese omelet with the use of the software. The data obtained as a consequence of the experimental study suggests that the activities carried out by the parents with the use of the software were found to be effective.
\end{abstract}

Keywords: applied behavior analysis, intellectual disability, skill teaching software, video modelling

\section{Introduction}

Intellectual disability is defined as significant deficiency affecting many social and practical skills in daily life in both mental functions and adaptive behaviors (AAMR, 2002). Intellectual disability makes it more difficult for people to perform some basic academic skills; such as remembering already learned contents, explaining why certain events happened, being able to estimate quantities, foreseeing consequences, adapting the already learned knowledge to new cases, analyzing relationships, comparing and contrasting two or more ideas (Cohen \& Spenciner, 2009). The most important purpose of education of intellectually disabled people is to help them increase their life qualities by improving their independent life skills.

Most of those with intellectual disability can gain some basic academic skills, such as reading and basic math. It is a necessity to help the individuals with intellectual disability gains some skills which are named as independent life skills as well as some academic skills. There are some classifications related to independent life skills. One of the most well-known of these classifications is the one done by Close, Sowers, Halpern and Bourbeau (1985). According to this classification, independent life skills are considered under four classifications as the basic skills necessary for achievement, the skills necessary for adaptation, daily life skills, vocational preparation and vocational skills.

The skills which are of first priority for achievement are some academic skills, such as numerical skills, reading and communication skills. Daily life skills include self-care skills, consumer skills, domestic skills, health care skills. Vocational skills include being prepared for job, vocational behaviors and social behaviors for vocational purposes (Cavkaytar, 1998).

As learning daily life skills decreases the level of dependency of intellectually disabled people on other people, it is considered to be of great significance for a successful adulthood life (Wu, 2011). Transition from school life into an independent life for a person with intellectual disability is quite an important period. Individuals are expected to have gained the minimum skills necessary for an independent life at the end of this period. Transition to an independent life may be very stressful and chaotic for those with intellectual disability. This transition period needs 
to be planned well and carefully by both parents and field experts. (Kyeong-Hwa \& Turnbull, 2004).

There are some studies carried out in the field revealing that fulfillment of daily life skills successfully by the people with intellectual disability increases self-confidence level of the people suffering from intellectual disability, and therefore, their life quality improves (Gooden-Ledbetter, Cole, Maher, \& Condeluci, 2007). Acquiring a profession for those with intellectual disability who continue their daily lives as independent individuals is obviously easier than that of those who have difficulty in fulfilling these skills in their lives (Wistow $\&$ Schneider, 2003). Moreover, lacking of such skills is suggested to cause exclusion of the people with intellectual disability by the society (Abbott \& McConkey, 2006; McConkey, Walsh-Gallagher, \& Sinclair, 2005; Hall, 2010).

Behavioristic approach and applied behavior analysis technique are the two most commonly used methods in the education of individuals with intellectual disability (Cooper, Heron \& Heward, 2007; Schreck \& Mazur, 2008; Welches \& Pica, 2005). The relevant literature reveals that behavioristic teaching methods can effectively be used to improve individuals' communication skills, social skills, daily life skills and academic skills (Brown, Percy, \& Machalek, 2007; Keenan, Henderson, Kerr, \& Dillenburger, 2006). Schreck and Mazur (2008) consider applied behavior analysis as a scientifically proven option.

Applied behavior analysis is used in teaching of adaptive behaviors to those individuals with intellectual disability in parallel with operant conditioning method. Applied behavior analysis is also used in decreasing and elimination of problematic behaviors of the individuals with intellectual disability (Neidert, Iwata, \& Dozier, 2005). The former and the succeeding variables are manipulated within experimental functional analysis of behaviors in applied behavior analysis (Najdowski, Wallace, Ellsworth, MacAleese, \& Cleveland, 2008). Dependent and independent variables are experimentally planned to examine the possibilities in behavioral setting (Cooper, Heron, \& Heward, 2007). Individuals are encouraged to fulfil the problematic behavior or the behavior intended to be taught and their achievement levels are measured. The same procedure is repeated in the analysis process of the fulfillment of the subject behavior by individuals. The data gathered is used to for the purpose of achieving the intended behavior.

The support given to parents who have children with intellectual disability as the people having the biggest effect on the intellectually disabled people's lives and inclusion of parents in the process of education of people with intellectual disability, have been important issues for long years (Cloth, 2006; Kim \& Morningstar, 2005; Vaden-Kiernan \& McManus, 2005; Özen, 2009). The researches carried out in the relevant literature demonstrate that parents are willing to participate in the education process of their children with intellectual disability (Hallahan, Lloyd, Kauffman, Weiss, \& Martinez, 2004; Özen, 2009). Moreover, the education given to the intellectually disabled people are considered to be one of the most basic variables improving the life quality of the families having intellectually disabled individuals.

Another issue in the education of the individuals with intellectual disability is educational technologies to be used. Whereas many researchers have claimed recently that some technology applications facilitate transition to general education and increase intellectually disabled students' achievement, technology is not used with full potential in the field of special education (Parsons, Daniels, Porter, \& Robertson, 2008, Woodward \& Reith, 1997). The reasons for that are considered to be that teachers lack some skills related to educational and supportive technologies, that teachers lack of knowledge about inclusion and curriculum, their tunnel vision and in service staff training (Judge \& Simms, 2009). In spite of some negativeness, it can be suggested that this negativeness can be resolved with various methods, that technology is full of the potential to enrich the lives of the individuals with intellectual disability and their families.

The educational technologies used in the education of the children with intellectual disability generally focus on teaching through videos. Most of these studies focus on the technique of video modelling. Video modelling simply video recording of a model as he/she is performing target behaviors and then letting learners view that recorded video. There are a lot of studies suggesting that video modelling technique can effectively be used in the education of individuals with intellectual disability (Bellini \& Akullian, 2007; Shukla-Mehta, Miller, \& Callahan, 2009; Charlop-Christy \& Daneshvar, 2003; Hine \& Wolery, 2006; Paterson \& Arco, 2007; Ayres \& Langone, 2008). In addition to that, Charlop-Christy, Le and Freeman (2000) have found that when video modelling is used, skills are learned quicker and can be generated better than that of live model technique. Video modelling technique is easy to learn with regards to practicality, less time consuming and makes it possible to offer a standardized education (Ayres \& Langone, 2005).

\section{Mobile Skill Teaching Software}

New mobile skill teaching software was developed for the parents of the individuals with intellectual disability within the scope of this project. As mentioned in the introduction part, family support is very significant in the 
education of the individuals with intellectual disability. The software developed with this regard, was developed for the use of parents. This software aims to train parents about individuals with intellectual disability as well as giving support to parents about educating individuals with intellectual disability. The name of the software is Independent Life Education (ILE). The software was developed in the form of a website accessible on the Internet, and it is available at bye.anadolu.edu.tr. Users are required to sign up on the homepage using the Sign UP button. It was a primary purpose to make the software easy to use on tablets in the development phase of the software.

Design based research method was used in the development of the software. Design based research is a process in which new applications like educational software and new hypothesis expected to affect teaching and learning, are investigated (Cobb, 2001; Brown, 1992). It can be effectively used in the cases when there are some design-related problems, such as activity design, educational message design, curriculum design, design of technology based educational environments (Kuzu, Çankaya, \& Misırl1, 2011). The software developed based on design-based research method, is grounded on theoretical basis and the use of the software without any problem by the participants is guaranteed working in cooperation with the participants.

There are six modules in the software; about, education, help, skill teaching, communication and personal. Under the "About" module is the knowledge about the research carried out and the members of the project team. Under the "Education" module is general knowledge about the individuals with intellectual disability and pedagogic content about how they should be educated about skill teaching. Under the "Help" module is information about how to use the software. Under the "skill teaching" module is the tools which are helpful in in skill teaching to those with intellectual disability. Under the "Communication" module are the tools to be used by users for communication purpose with experts. Users can update their personal information using the "Personal" module.

The part that parents benefit from in the planning of skill teaching and application of the skill teaching is the "skill teaching" module of the software. This module is developed based on the applied handbook "Özel Gereksinimi Olan Çocuklara özbakım ve Ev içi becerileri Öğretimi”" (Teaching self-care and domestic skills to the children with intellectual disability) written by Cavkaytar (2005). There are 18 self-care and domestic skill analyses prepared by the experts of special education under the "skill teaching" module. The parents who want to do skill teaching primarily need to do planning for the skills to be taught. Firstly, parents decide on the skills to be taught under "skill teaching" module. After deciding on the skills to be taught, the orders of the skills to be taught need to be determined. After determining the order of teaching, detailed action plan is prepared, such as the purpose of the study for the skills to be taught, the place where the study will be carried out, the tools and instruments to be used in the study. Moreover, the rewards of the study should also be determined at the planning stage of the study.

When it is time to perform the pre-determined actions planned in skill teaching module, the skill teaching works need to be done by parents. The parents who perform the skill teaching task, need to enter the performance related information about the intellectually disabled person to the system. Thus, parents can obtain reports about their past performance whenever they want.

There are multimedia contents which parents can make use of in their skill teaching activities in the software. These multimedia contents are video modelling, picture, animation, illustration and narration. As mentioned in the introduction part of the study, video modeling technology has been commonly and effectively used in the education of the individuals with intellectual disability. Animation videos, in which a cartoon character is presented as a model, were prepared and loaded to the system. Picture and illustration are motionless images for skill stages taken from video modelling and animation. As parents are allowed to let their children watch the video modelling and animation including all skill stages prior to the teaching, they can also let their children watch the video modellings, picture, animation and illustration related to the specific skill stages which their children have difficulty with. At the same time, narration contents are also available in the software to be used in skill teaching in the form of instruction. More information about the software, how it was developed and it theoretical backgrounds can be found in the article "development of mobile skill teaching software for parents of individuals with intellectual disability" (Kuzu, Cavkaytar, Odabaşı, Erişti, \& Çankaya, 2014).

Parents' awareness of the teaching techniques which have been proved to be effective in the education of the individuals with intellectual disability in the literature, such as applied behavior analysis and video modelling, to be able use them effectively and applications related to technological support to parents in this sense, and making further research on the effectiveness of such applications, are all very important. With this regard, the purpose of this research is to examine the effectiveness of the mobile skill teaching software which has been developed for the use of the parents who have intellectually disabled children. 


\section{Method}

In this part, information about the research model, choosing the participants, data collection and data analysis is provided.

\subsection{Research Model}

To be able to investigate the effectiveness of the mobile skill teaching software which has been developed for the benefit of the parents having intellectually disabled children, multiple probe design with probe conditions across subjects' research methodology is used. The independent variable of the study is the teaching activities of the participants which they performed with the help of newly developed ILE software, and the dependent variable of the study is if the individuals with intellectual disability could learn the skills taught by the participants. Multiple probe design with probe conditions across subjects' research methodology is a model which is based on evaluation of the effectiveness of a teaching or behavior modification program on more than one subject. The teaching of one certain skill in this model should be done on at least three participants.

A research process which is carried out in multiple probe design with probe conditions across subjects' research methodology makes progress in the following way. The data gathered at the baseline phase is simultaneously taken to reveal the performances of the intellectually disabled individuals on a certain skill. If the single opportunity method is chosen in data collection at the baseline phase, the person with intellectual disability is given only the instruction to perform the related skill, and no other aid is provided. If individuals fail in performing a skill phase, the study is terminated, and individuals are not allowed to continue with the other phases.

After gathering the data related to the baseline phase from all the participants, only one of them should be subject to the teaching sessions. Other participants should be kept waiting, and they should never be allowed to be involved in any activity related to the skills being studied. The teaching sessions of the intellectually disabled individual who is the first to start the sessions, end up with a full freedom in performing all skill stages. In some cases, an $80 \%$ achievement is considered as success. When the sessions of the intellectually disabled individual which is the first to start the teaching sessions are over, a simultaneous data collection from all individuals is performed. In other words, at the end of each teaching session, a simultaneous baseline data for individuals, who have not started to be taught, and follow-up data for individuals, who have been taught, should be collected from all individuals, including those who have not started their teaching sessions yet. After gathering baseline and follow-up data, it is time for the next intellectually disabled individual to start the teaching session with. When all teaching sessions are completed, a final follow-up data is collected from all intellectually disabled individuals, and the procedure is completed in this way (Kırcaali-İftar \& Tekin, 1997).

\subsection{Participants}

Four participants were chosen in this study. This process which is completed through multiple probe design with probe conditions across subjects' research methodology is a time consuming and laboring process for the participants. Some of the participants are known beforehand by the staff taking charge in this study. Considering this, four participants were chosen providing that they would participate in the process and would not disrupt, and their approvals were received. Three participants are enough for this model. However, one extra participant was chosen considering that a misfortune may happen in the following stages. The information gathered from the participants and the tablets distributed to them as part of the project and the information related to the individuals with intellectual disability is given in Table 1 .

Table 1. Participants of the study

\begin{tabular}{|c|c|c|c|c|c|c|c|}
\hline \multirow{2}{*}{ Participant } & \multirow{2}{*}{ Intimacy } & \multirow{2}{*}{ Age } & \multirow{2}{*}{ Educational Status } & \multirow{2}{*}{ The device used } & \multicolumn{3}{|c|}{ Of the individual with intellectual disability } \\
\hline & & & & & Gender & Age & Disability Status \\
\hline Participant 1 & Mother & 42 & Foundation degree & Galaxy Tab & Male & 16 & Down Syndrome \\
\hline Participant 2 & Mother & 45 & High School & Galaxy Tab & Male & 21 & $\begin{array}{l}58 \% \text { intellectual } \\
\text { disability }\end{array}$ \\
\hline Participant 3 & $\begin{array}{l}\text { Grand } \\
\text { mother }\end{array}$ & 60 & Secondary School & Galaxy Tab & Female & 19 & $\begin{array}{c}40 \% \text { intellectual } \\
\text { disability }\end{array}$ \\
\hline Participant 4 & Mother & 53 & Secondary School & iPad & Male & 31 & Down Syndrome \\
\hline
\end{tabular}

Some prior conditions have been set in the choice of the participants and the individuals with intellectual disability so that the study can be conducted in a healthy way, and these conditions are always kept in mind. It was a prior 
condition to be a graduate of at least secondary schools for the participants so that they could use the ILE software on their tablets and could record the performance data of their child, and that they could understand the written material by reading. As a dense and demanding process will be experienced for the participants, it is necessary for them to volunteer for that. For the individuals with intellectual disability, it is a prior condition to be adults and not to have any physical disability which will hinder them from performing any skills, and this is always kept in mind.

Three meetings were organized with the participants. In the first of these meetings, the participants were trained about how to use the tablets they were provided. In the second meeting, they were briefed about how they could do skill teaching by using ILE software. In the third meeting, the participants were given information about the research process, and there was an attempt to find out a shared skill which intellectually disabled individuals could not perform in common. No shared skill was able to be found in the system; therefore, a new skill was looked for. Finally, the skill of making cheese omelet was chosen as suggested by the participants. The analysis of this skill and multimedia contents are prepared and loaded to the software.

\subsection{Data Collection}

The data related to the baseline, teaching and follow-up phases was collected to measure the performance of the intellectually disabled individuals on the skill of making cheese omelet. All the sessions were video recorded. These video recordings were investigated by a special education expert. The assessment form given in Table 2 was used for the evaluation. As can be seen in the form, there are the skill stages of making cheese omelet to be performed step by step by the intellectually disabled individuals. Attached to the skill stages is the performance of the intellectually disabled individuals in the relevant skill stage. The data given in Table 2 is given as an example. Similarly to the data given in this table, it is pointed out if the individual with intellectual disability fulfils the relevant skill stage independently $(+)$, or with a verbal clue (V), modelling $(\mathrm{M})$ or with a physical aid $(\mathrm{P})$. The participant who could complete the skill teaching in the least session (four sessions) is the participant 7 . In other words, the son of the participant 7 could learn the taught skill in four sessions. In this case, one data collection at the baseline phase, four data collections at the teaching period and four data collections at the follow-up phase were done from the participant 7 . Therefore, 9 sessions and 9 video recordings were carried out.

Table 2. Sample evaluation form

\begin{tabular}{|c|c|c|c|c|}
\hline \multirow{2}{*}{ Skill Stages } & \multicolumn{4}{|c|}{ Sessions } \\
\hline & 1 & 2 & 3 & 4 \\
\hline Places the cookware necessary for making omelet on the countertop & $\mathrm{S}$ & + & + & + \\
\hline Cuts some cheese with a knife & $\mathrm{F}$ & $\mathrm{S}$ & + & + \\
\hline Keeps the cut cheese with a fork and places on a plate & + & + & + & + \\
\hline Crumbles the cheese pulverizing with a fork. & $\mathrm{S}$ & + & + & + \\
\hline Breaks the first egg hitting to the edge of the plate or pan & M & $\mathrm{S}$ & $\mathrm{S}$ & + \\
\hline Empties the egg content into the plate with pulverized cheese, and puts the egg shell into the bin. & M & $\mathrm{S}$ & + & + \\
\hline Breaks the second egg slightly hitting it to the edge of the plate or pan. & $\mathrm{S}$ & $\mathrm{S}$ & + & + \\
\hline Empties the content of the egg into the plate and puts the egg shells into the bin. & $\mathrm{S}$ & $\mathrm{S}$ & + & + \\
\hline Washes his/her eggy hands and then dries. & $\mathrm{S}$ & + & + & + \\
\hline Puts some salt into the same plate & $\mathrm{S}$ & $\mathrm{S}$ & $\mathrm{S}$ & + \\
\hline Adds some black pepper into the same plate. & + & + & + & + \\
\hline Mixes the mixture in the dish with a fork. & + & + & + & + \\
\hline Puts some oil into the pan. & $\mathrm{S}$ & + & + & + \\
\hline Places on the fire. & $\mathrm{F}$ & M & $\mathrm{S}$ & + \\
\hline Places the pan on the fire & + & + & + & + \\
\hline Moves the pan from side to other side to let the whole part get oily & $\mathrm{S}$ & $\mathrm{S}$ & + & + \\
\hline After letting the pan get heat for a while, adds the eggy mixture into the pan. & $\mathrm{S}$ & $\mathrm{S}$ & $\mathrm{S}$ & + \\
\hline Moving the pan on the fire, cooks the egg without letting the egg stick to the pan. & + & + & + & + \\
\hline When the bottom of the egg roast enough, the egg is turned down with a spatula. & $\mathrm{F}$ & $\mathrm{F}$ & $\mathrm{S}$ & + \\
\hline Cooks the egg for a while moving the pan from side to side. & $\mathrm{S}$ & $\mathrm{S}$ & + & + \\
\hline After the other side roasts, places the pan on an off cooker. & $\mathrm{S}$ & + & + & + \\
\hline Switches off the cooker. & $\mathrm{S}$ & $\mathrm{S}$ & + & + \\
\hline Lifts the egg from the pan with a spatula and places on a plate. & $\mathrm{S}$ & + & + & + \\
\hline TOTAL & 5 & 11 & 18 & 23 \\
\hline PERCENTAGE & 22 & 48 & 78 & 100 \\
\hline
\end{tabular}


All participants were invited to the house of the researcher to be able to gather the data related to the baseline and follow-up. Two special education experts were ready in the meetings that all participants participated, and they guided the participants. 5 meetings were organized to collect baseline and follow-up data.

The participants and children were taken to the kitchen in order, and the process were video recorded for the data collection related to the baseline and follow-up phase. Prior to the study, the participants were informed what kind of ways they would follow to gather data related to the baseline and follow-up phases. The participants ordered the intellectually disabled individual to make a cheese omelet and no other aid was given. Participants interfered their children if their children failed at any stage and stopped the process. When data collection is in progress with one participant, the other ones were kept waiting in the guestroom. As data was collected in baseline and follow-up phases, single opportunity method was used. In other words, when an intellectually disabled individual made a mistake at a stage, the study was terminated. When the video recordings were evaluated, the parts following the terminated stage were noted as "could not do".

Multiple Opportunity method was used in the teaching activities carried out by the participants. Participants were informed about how they could apply multiple opportunity method.

The data related to the baseline phase was gathered from all participants on 23/09/2012. In summary, four intellectually disabled individuals were found to have lower performance level in the skill of making cheese omelet. After gathering the data related to the baseline phase, interviews were conducted with the participants, and they were informed about the process. Then, considering the direction taken from the participants, the order of teaching was determined. According to this teaching schedule, the first family (Participant 4) started the teaching sessions.

Home visits were organized for all participants before the teaching sessions started. The participants were informed about how the educational activities would be conducted with the use of ILE software, and the participants were requested to do the first teaching activity together with three researchers. Thus, possible malpractices were prevented well in advance.

In teaching sessions the individuals with intellectual disability were allowed to watch the video model in the software covering all skill stages and then the children were demanded to perform the same skill. When children hesitate in any stage appropriate aid was provided through appropriate clue giving technique. The participants' video recorded the sessions which they attended. Participants were provided with a video camera and a tripod so that they could record their activities. Participants were also informed about how to use the video camera in the first teaching activity. Participants placed the video camcorders in an appropriate place in the kitchen before the teaching session started and pressed the record button. Some of the participants did not use tripod during the recording as their kitchens were not spacious enough, and they made one of their family members do the recording for them.

As the participant 4 performing their teaching sessions, the other participants are expected not to do any activity related to the skill of omelet making. This was explained to the participants. At the same time, the other three participants' access to the pages related to the skills of making cheese omelet, were blocked on the ILE software, and they could not view the relevant videos on the software. Participant 4 completed the teaching phase in four sessions. In other words, the child of participant 4 could independently achieve to complete all the skill stages without getting any clue from parents.

After participant 4 completed the teaching activities, all participants were gathered on 21-10-2012 again and the baseline and follow-up data was collected. Then the other participant (Participant 3) started the teaching activities. The participant 3 who performed his first teaching activity under the supervision of the researcher, completed the teaching activities in 8 sessions.

When the participant 3 completed the teaching activities, all participants were gathered for the collection of baseline and follow-up data on 25-11-2012. Then the next participant (Participant 2) started the teaching activities. The participant 2 who performed his first teaching activity under the supervision of the researcher, completed the teaching activities in 10 sessions. Participant 2 terminated teaching activities after 10 sessions. When Participant 2 completed the teaching activities, all participants were gathered again on 23-12-2012 and baseline and follow-up data was collected. Then the last participant (Participant 1) started the teaching activities. The participant 1 who completed his first teaching session under the supervision of the researchers, completed his teaching activities in 10 sessions.

With the completion of the teaching activities performed by the Participant 1, all participants have completed their tasks. At the end of this period, all participants were gathered again on 22-01-2013, and the last follow-up data was 
collected. Thus data collection procedure has been completed.

\subsection{Data Analysis}

In the data collection process, 32 teaching activities and 20 data collection practices related to baseline and follow-up phases were carried out. 52 videos recorded in this study were viewed by a special education expert, and the performances of the intellectually disabled individuals were determined (the percentage of skill stages carried out independently). The performance related data collected in the study were computerized to Microsoft Excel 2010 and were analyzed graphically. In the analysis of the data, linear graph which is one of the graphical analysis techniques, was used.

Intellectually disabled individuals' level of fulfillment of the relevant skill stages; in other words, the scores related to their performance, were calculated in percentages and displayed in equal intervals between $0-100$ on the coordinate plane. The sessions carried out in the baseline, teaching and follow-up phases are seen on the $\mathrm{X}$ axis. Every dot on the graph stands for a session.

\section{Findings}

The findings and discussions related to the effect of the ILE software on the intellectually disabled individuals' achievement after skill teachings carried out, are presented in this part. All the data collected at the baseline, follow-up and teaching activities were evaluated and summed up in the linear graph. In the linear graph, the data of the Participant 4 who started the teaching activities the first was given. In the second, third and fourth rank is graph of the data obtained from the participant 3 , participant 2 and participant 1. 


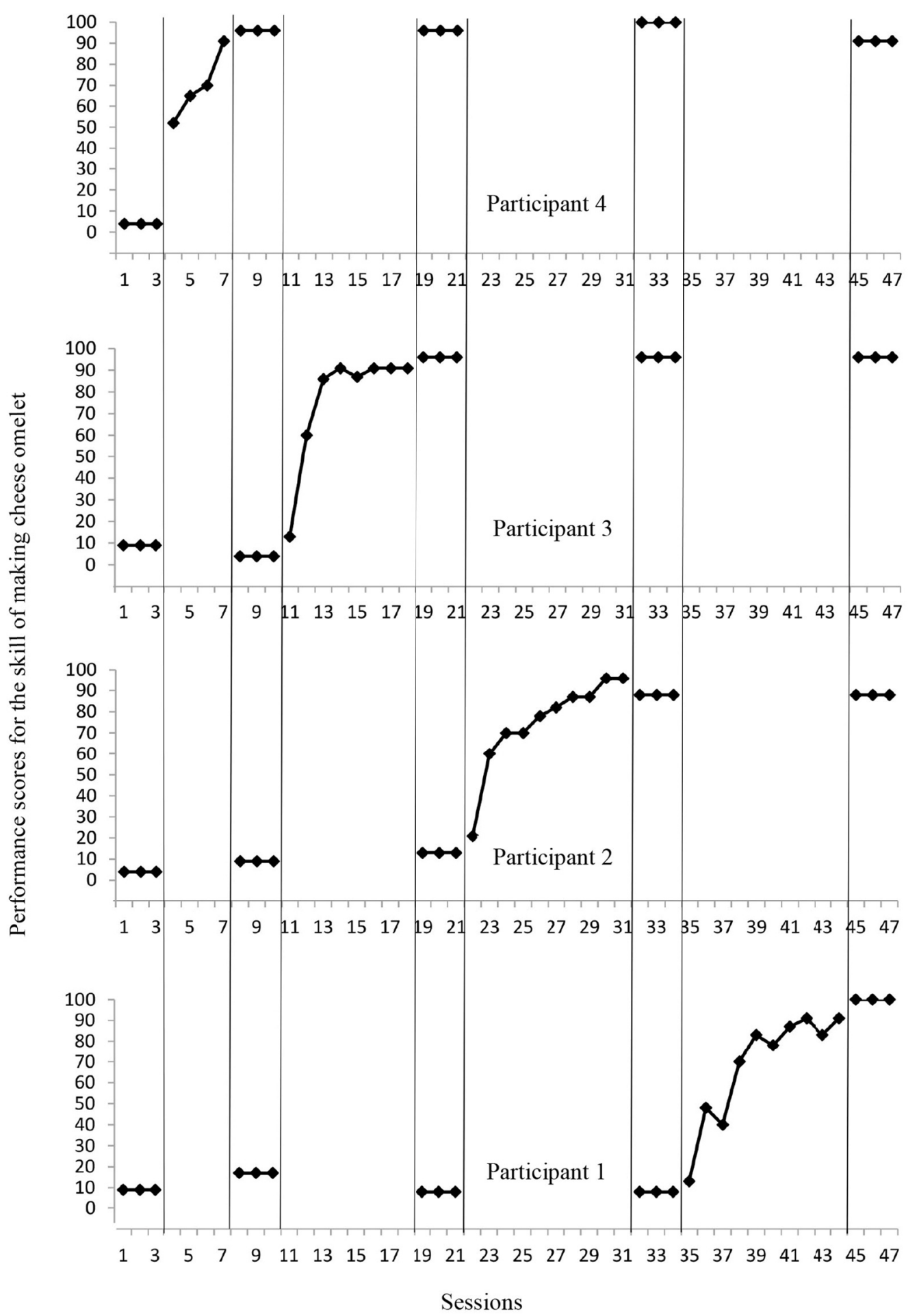

Figure 1. The effectiveness of teaching activities with the use of ILE software

When the Figure 1 is examined, it is clear that the intellectually disabled individuals participating in the study had no performance at the beginning of the study, about " 0 " level. After finding out that the individuals with intellectual disability had no skill of making cheese omelet in the past, the experimental process went on with Participant 4. Following the four teaching sessions carried out in the study, the child of participant 4 was found to have learned the skill of making cheese omelet. Considering this, it can be suggested that the skill teaching that the 
participant 4 carried out with his son was effective. After the first participant displayed performance as much as demanded, all participants were gathered again for baseline and follow-up sessions. In the session, no individuals with intellectual disability have experienced a change in their skill of making cheese omelet except the son of Participant 4. This case makes us think that only the participant who is exposed to the experimental process experienced change in his performance, and that makes us think that it is a consequence of the implementation.

In the next part of the study, implementation was done with participant 3, participant 2 and participant 1 in order. As can be seen from the graph above, the performances of the participants' children increased about $100 \%$ following the teaching sessions. Besides, the fact that the children who gained the skill after the relevant teaching session also displayed similar performances in the next follow-up sessions demonstrate that these skills have been permanently learned by them.

\section{Conclusion}

A mobile skill teaching software was developed based on some theoretical principles such as applied behavior analysis, video modelling technique, contribution of parents to their intellectually disabled children's education. As in the studies carried out on the intellectually disabled individuals, single subject research model is used in the skill teaching activities and in the cases when the number of participant is a few (Kurcaali-İftar \& Tekin, 1997). With this regard, to be able to scientifically claim if the teaching activities that the participants carried out is a real success; in other words, to find out how effective the software is, a study was carried out using the multiple probe design, which is one of the single subject research models. Under the light of the data obtained with this study, it is seen that intellectually disabled individuals learn the taught skills following the skill teaching activities performed with the use of the ILE software. This indicates that the developed software was effective and that it could be effectively used in the skill teaching activities to intellectually disabled individuals.

When the relevant literature is examined, there have been various parental education programs investigating the competences; such as finding out the educational needs of intellectually disabled individuals and carrying out educational activities considering these needs, planning this process and evaluating it. These studies generally suggest that involving parents of the intellectually disabled individuals in educational processes has effective contribution to their learning (Cavkaytar, 1998; Cloth, 2006; Kim \& Morningstar, 2005; Vaden-Kiernan \& McManus, 2005). This study has come up with findings supporting the literature which suggests that the effective involvement of family members in the education of their intellectually disabled children is significant. However, no study has been found in the literature which uses mobile skill teaching software which involves parents in their intellectually disabled children's skill teaching processes.

Although there have been many programs which require the use of family members as educators, no implementation has been found in the literature requiring the use of such programs online. The online support given to parents and the intellectually disabled children and carrying out the applied research about the education given to children by parents using such environments are expected to have significant contribution to this issue

\section{Acknowledgements}

This paper is based on the first author's PhD dissertation supervised by the second author and supported in part by a grant from The Scientific and Technological Research Council of Turkey (TUBITAK)

\section{References}

AAMR. (2002). Mental retardation: definition, classification, and systems of supports. Washington: American Association on Mental Retardation.

Abbott, S., \& McConkey, R. (2006). The barriers to social inclusion as perceived by people with intellectual disabilities. Journal of Intellectual Disabilities, 10(3), 275-287. https://doi.org/10.1177/1744629506067618

Ayres, K. M., \& Langone, J. (2008). Video Supports for Teaching Students with Developmental Disabilities and Autism: Twenty-Five Years of Research and Development. Journal of Special Education Technology, 23(3), 1-8. https://doi.org/10.1177/016264340802300301

Bellini, S., \& Akullian, J. (2007). A meta-analysis of video modeling and video self-modeling interventions for children and adolescents with autism spectrum disorders. Exceptional Children, 73(3), 264-287. https://doi.org/10.1177/001440290707300301

Brown, A. L. (1992). Design experiments: Theoretical and methodological challenges in creating complex interventions in classroom settings. Journal of the Learning Sciences, 2(2), 141-178. https://doi.org/10.1207/s15327809j1s0202_2

Brown, I., Percy, M., \& Machalek, K. (2007). Education for individuals with intellectual and developmental 
disabilities. In I. Brown, M. Percy, \& H. Paul (Eds.), Comprehensive guide to intellectual \& developmental disabilities (pp.489-510). Baltimore, Maryland: Brookes Publishing Co.

Cavkaytar, A. (1998). Zihin engellilere öz bakım ve ev içi becerilerinin ögretiminde bir aile programının etkililiği (Unpublished doctoral dissertation). Anadolu Üniversitesi, Sosyal Bilimler Enstitüsü, Eskişehir.

Cavkaytar, A. (2005). Özel gereksinimi olan çocuklara özbakım ve ev içi becerilerinin ögrretimi: Uygulamalı el kitabı. Ankara: Gündüz Eğitim ve Yayıncılık.

Charlop-Christy, M. H., \& Daneshvar, S. (2003). Using video modeling to teach perspective taking to children with autism. Journal of Positive Behavior Interventions, 5 , 21. https://doi.org/10.1177/10983007030050010101

Charlop-Christy, M. H., Le, L., \& Freeman, K. A. (2000). A comparison of video modeling with in vivo modeling for teaching children with autism. Journal of Autism and Developmental Disorders, 30(6), 537-552. https://doi.org/10.1023/A:1005635326276

Close, D. W., Sowers, J., Halpern, A., \& Bourbeau, P. E. (1985). Programming for the transition to independent living for mentally retarded persons. In K. C. Lakin \& R. H. Bruininks (Eds.), Strategies for achieving community integration of developmentally disabled citizens (pp.161-176). Baltimore: Brookes.

Cloth, A. H. (2006). Navigation efficacy among parents of public school Children with special needs (Unpublished doctoral dissertation). Faculty of the Graduate School of the University of Texas at Austin.

Cobb, P. (2001). Supporting the improvement of learning and teaching in social and institutional contex. In S. Carver, \& D. Klahr (Eds.), Cognition and instruction: Twenty-five years of progress (pp. 455-478). Cambridge, MA: Lawrence Erlbaum Associates.

Cohen, L., \& Spenciner, L. (2009). Teaching learners with mild and moderate disabilities: Research-based practices. Boston, MA: Allyn \& Bacon.

Cooper, J. O., Heron, T. E., \& Heward, W. L. (2007). Applied behavior analysis (2nd ed.). Upper Saddle River, NJ: Pearson Prentice Hall.

Gooden-Ledbetter, M. J., Cole, M. T., Maher, J. K., \& Condeluci, A. (2007). Self-efficacy and interdependence as predictors of life satisfaction for people with disabilities: Implications for independent living programs. Journal of Vocational Rehabilitation, 27(3), 153-161.

Hall, S. A. (2010). The social inclusion of young adults with intellectual disabilities: a phenomenology of their experiences (Unpublished doctoral dissertation). Faculty of The Graduate College at the University of Nebraska.

Hallahan, D. P., Lloyd, J. W., Kauffman, J. M., Weiss, M. P., \& Martinez, E. A. (2004). Learning disabilities: Foundations, characteristics, and effective teaching (3rd ed.). Boston: Allyn \& Bacon.

Hine, J. F., \& Wolery, M. (2006). Using point-of-view video modeling to teach play to preschoolers with autism. Topics in Early Childhood Special Education, 26, 83-93. https://doi.org/10.1177/02711214060260020301

Judge, S., \& Simms, K. A. (2009). Assistive technology training at the pre-service level: A national snapshot of teacher preparation programs. Teacher Education and Special Education, 32(1), 33-44. https://doi.org/10.1177/0888406408330868

Keenan, M., Henderson, M., Kerr, K. P., \& Dillenburger, K. (2006). Applied behaviour analysis and autism: Building a future together. London: Jessica Kingsley Publishers.

Kim, K. H., \& Morningstar, M. E. (2005). Transition planning involving culturally and linguistically diverse families. Career Development for Exceptional Individuals, 28(2), 92-103. https://doi.org/10.1177/08857288050280020601

Kırcaali-İftar, G., \& Tekin, E. (1997). Tek denekli araştırma yöntemleri. Ankara: Türk Psikologlar Derneği Yayınları.

Kuzu, A., Cankaya, S., \& Misirli, Z. A. (2011). Design-Based Research and Its Implementation in the Design and Development of Learning Environments. Anadolu Journal of Educational Sciences International, 1(1), 19-35.

Kuzu, A., Cavkaytar, A., Odabaşı, H. F., Erişti, S. D., \& Çankaya, S. (2014). Development of mobile skill teaching software for parents of individuals with intellectual disability. Turkish Online Journal of Qualitative Inquiry, 5(2), 11-26. https://doi.org/10.17569/tojqi.24629 
Kyeong-Hwa, K., \& Turnbull, A. (2004). Transition to adulthood for students with severe intellectual disabilities: Shifting toward person-family interdependent planning. Research \& Practice for Persons with Severe Disabilities, 29(1), 53-57.

McConkey, R., Walsh-Gallagher, D., \& Sinclair, M. (2005). Social inclusion of people with intellectual disabilities: The impact of place of residence. Irish Journal of Psychological Medicine, 22(1), 10-14. https://doi.org/10.1017/S0790966700008727

Najdowski, A. N., Wallace, M. D., Ellsworth, C. L., MacAleese, A. N., \& Cleveland, J. M. (2008). Functional analyses and treatment of precursor behavior. Journal of Applied Behavior Analysis, 41(1), 97-105. https://doi.org/10.1901/jaba.2008.41-97

Neidert, P., Iwata, B., \& Dozier, C. (2005). Treatment of multiply controlled problem behavior with procedural variations of differential reinforcement. Exceptionality, 13(1), 45-53. https://doi.org/10.1207/s15327035ex1301_6

Özen, A. (2009). Davranış değiştirme ve öğrenim sürecinde aile. In E. Tekin İftar (Ed.), Davranış ve ögrenme sorunu olan çocukların eğitimi (pp. 63-82), Eskişehir: Anadolu Üniversitesi Yayını.

Parsons, S., Daniels, H., Porter, J., \& Robertson, C. (2008). Resources, staff beliefs and organizational culture: factors in the use of information and communication technology for adults with intellectual disabilities. Journal of Applied Research in Intellectual Disabilities, 21(1), 19-33.

Paterson, C. R., \& Arco, L. (2007). Using video modeling for generalizing toy play in children with autism. Behavior Modification, 31, 660-681. https://doi.org/10.1177/0145445507301651

Schreck, K., \& Mazur, A. (2008). Behavior analyst use of and beliefs in treatments for people with autism. Behavioral Interventions, 23(3), 201-212. https://doi.org/10.1002/bin.264

Shukla-Mehta, S., Miller, T., \& Callahan, K. J. (2010). Evaluating the effectiveness of video instruction on social and communication skills training for children with autism spectrum disorders: a review of the literature. Focus on Autism and Other Developmental Disabilities, 25(1), 23-36. https://doi.org/10.1177/1088357609352901

Vaden-Kiernan, N., \& McManus, J. (2005). Parent and family involvement in education: 2002-03. Washington, DC: Institute of Education Sciences U.S. Department of Education.

Welches, P., \& Pica, M. (2005). Functional analysis of behavior: A collaborative phenomenological approach. The Humanistic Psychologist, 33(1), 59-68. https://doi.org/10.1207/s15473333thp3301_6

Wistow, R., \& Schneider, J. (2003). Users' views on supported employment and social inclusion: A qualitative study of 30 people in work. British Journal of Learning Disabilities, 31(4), 128-135. https://doi.org/10.1111/j.1468-3156.2003.00253.x

Woodward, J., \& Rieth, H. (1997). A historical review of technology research in special education. Review of Educational Research, 67, 503-536. https://doi.org/10.3102/00346543067004503

$\mathrm{Wu}$, P. F. (2011). The effects of video prompting and activity schedules on the acquisition of independent living skills of students who are deaf and have developmental disabilities (Unpublished master's thesis). Graduate School of The Ohio State University.

\section{Copyrights}

Copyright for this article is retained by the author(s), with first publication rights granted to the journal.

This is an open-access article distributed under the terms and conditions of the Creative Commons Attribution license (http://creativecommons.org/licenses/by/4.0/). 